\title{
Implications of Trophic Variability for Modeling Biomagnification of POPs in Marine Food Webs in the Svalbard Archipelago
}

\author{
Renske P. J. Hoondert, * Nico W. van den Brink, Martine J. van den Heuvel-Greve, AdM. J. Ragas, \\ and A. Jan Hendriks
}

Cite This: Environ. Sci. Technol. 2020, 54, 4026-4035

Read Online

\section{ACCESS |}

Џlll Metrics \& More

Article Recommendations

Supporting Information

ABSTRACT: The occurrence of persistent organic pollutants (POPs) in the Arctic has been of constant concern, as these chemicals cause reproductive effects and mortality in organisms. The Arctic acts as a chemical sink, which makes this system an interesting case for bioaccumulation studies. However, as conducting empirical studies for all Arctic species and POPs individually is unfeasible, in silico methods have been developed. Existing bioaccumulation models are predominately validated for temperate food chains, and do not account for a large variation in trophic levels. This study applies Monte Carlo simulations to account for variability in trophic ecology on Svalbard when predicting bioaccumulation of POPs using the optimal modeling for ecotoxicological applications (OMEGA) bioaccumulation

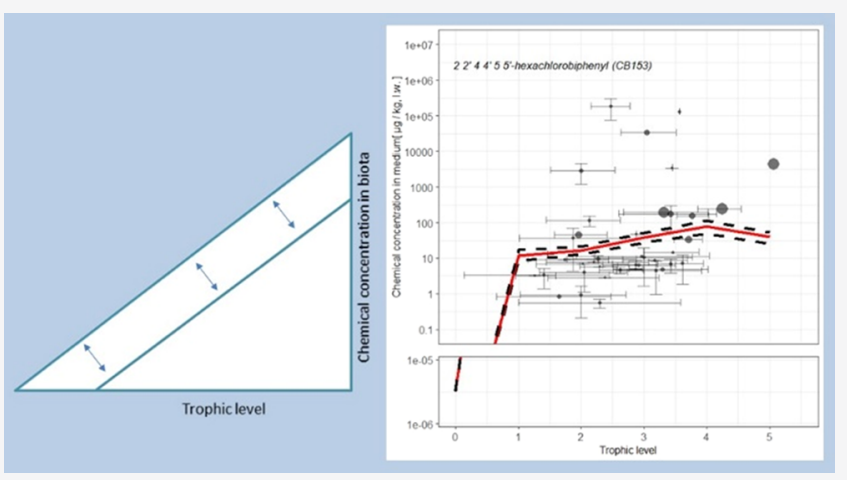
model. Trophic magnification factors (TMFs) were calculated accordingly. Comparing our model results with monitored POP residues in biota revealed that, on average, all predictions fell within a factor 6 of the monitored POP residues in biota. Trophic variability did not affect model performance tremendously, with up to a $25 \%$ variability in performance metrics. To our knowledge, we were the first to include trophic variability in predicting biomagnification in Arctic ecosystems using a mechanistic biomagnification model. However, considerable amounts of data are required to quantify the implications of trophic variability on biomagnification of POPs in Arctic food webs.

\section{INTRODUCTION}

Persistent organic pollutants (POPs) in the Arctic have been of concern since the mid-1980s. These compounds are known to cause adverse effects (e.g., altered reproduction and immunological effects in organisms at higher trophic levels). ${ }^{1-4}$ Despite the banning of many of these compounds in the 1970s and 1980s, high levels of POPs are still being reported in Arctic biota. This is due to the combination of chemical properties of POPs in cold conditions (e.g., high thermal stability and slow degradation) and marine currents and airflows transporting POPs northwards. ${ }^{5-10}$ Due to the accumulation of chemicals via limited evaporation at lower temperatures and recirculating air and water currents, ${ }^{11}$ the Arctic is a global chemical sink. This makes the Arctic a relevant case for bioaccumulation studies. $^{12-14}$ The magnification potential of chemicals is evaluated by calculating trophic magnification factors (TMFs), reflecting the degree of magnification of the chemical throughout the food chain. These TMFs are defined as the slopes of the log-transformed contaminant concentrations (in lipid weight) on trophic position and rely heavily on monitoring data or experimental studies. ${ }^{15}$ Although the TMF concept is accepted as one of the most realistic quantitative measures of biomagnification, ${ }^{16}$ there is a lack of studies assessing changes of TMFs across large spatial scales and ecosystems. ${ }^{17}$ Conducting extensive empirical studies for all Arctic species and POPs individually is unfeasible, due to ethical, financial, and practical constraints. ${ }^{18}$ Furthermore, TMF measurements are retrospective and are only feasible after a substance has already been released into the environment. $^{16}$ As TMFs are based on univariate linear regression models, these do not account for species-specific biotransformation of POPs. ${ }^{19}$ In silico mechanistic methods have been developed to predict biomagnification of hazardous compounds in food chains, including models describing bioaccumulation kinetics. $^{20-22}$ These models generally require water concentration and the trophic position of a species in a particular food chain as input, as well as specific species traits (e.g., body mass and lipid content) and chemical-specific characteristics (e.g., the octanol-water partition coefficient).

Received: November 5, 2019

Revised: February 12, 2020

Accepted: March 4, 2020

Published: March 4, 2020

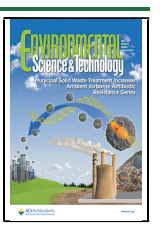


Bioaccumulation models are predominately validated for temperate food chains. ${ }^{21,23,24}$ The Arctic is highly influenced by seasonality, which affects the degree of bioaccumulation of compounds in Arctic food webs throughout the year. ${ }^{25-28}$ Seasonal differences in the Arctic are mainly driven by fluctuations in light, temperature, and sea ice affecting phytoplankton blooms, the species' lipid content, and body size. This in turn may affect the community structure and, therefore, food and prey availability and may consequently lead to diet shifts. ${ }^{25,27,28}$ Variation in the baseline species and temporal and spatial differences in trophic status of species can have substantial implications for the performance of the biomagnification model. ${ }^{29,30}$ Although the influence of trophic variability of species in Arctic ecosystems on the transfer of POPs in food webs has been previously studied, ${ }^{17}$ its influence on the performance of mechanistic biomagnification and bioaccumulation models is yet to be examined. Intrinsic trophic variability and diet shifts throughout the year may lead to differences in steady-state concentrations of POPs in Arctic species. The aim of the current study was to better predict the bioaccumulation of POPs in Arctic food chains, which are subjected to high trophic variability using the optimal modeling for ecotoxicological applications (OMEGA) bioaccumulation model. Publicly available data for one Arctic region, i.e., Svalbard, were used as input for the mechanistic biomagnification model to predict the transfer of POPs across food chains, accounting for variability in the trophic position of species by means of Monte Carlo simulations. Model performance data were evaluated against measured POP concentrations in the Svalbard Archipelago.

\section{MATERIALS AND METHODS}

The OMEGA Bioaccumulation Model. Model Approach. Biomagnification of POPs in the present study was calculated using the OMEGA bioaccumulation model, ${ }^{31}$ combining mass balance and allometric approaches to estimate bioaccumulation in each tropic level individually and biomagnification throughout the food chain. ${ }^{24}$ Since its development, OMEGA has effectively been applied in estimating biomagnification of numerous organic compounds and metals. ${ }^{23-25}$ We assumed a steady-state concentration of chemical residues in aquatic organisms $\left(C_{i, x}\right.$, in $\mu \mathrm{g} / \mathrm{kg}$ lipid weight (l.w.)), calculated as the sum of influx via water (absorption) and uptake from food (assimilation) divided by the total elimination rate, encompassing elimination via water, biotransformation, excretion, and dilution through growth, disregarding possible uptake and elimination through air. The steady-state concentration in an organism is calculated as ${ }^{31}$

$$
C_{i, x}=\frac{\left(k_{0, x, \text { in }} \cdot C_{0, w, x}+k_{1, x, \text { in }} \cdot C_{i-1, x}\right)}{\sum_{j}^{4} k_{j, x, \text { out }}}
$$

where $C_{i, x}$ is defined as the final steady-state concentration of substance $x$ at trophic level $i$ (in $\mu \mathrm{g} / \mathrm{kg}$ lipid weight), $k_{0, x, \text { in }}$ is the chemical absorption rate (in $\mathrm{L} / \mathrm{kg} \cdot \mathrm{d}^{-1}$ ), $C_{0, w, x}$ is the initial chemical concentration in the water (in $\mu \mathrm{g} / \mathrm{L}$ ), $k_{1, x, i n}$ is the chemical concentration assimilation rate in $\left[\mathrm{kg} / \mathrm{kg} \cdot \mathrm{d}^{-1}\right], C_{i-1, x}$ is the chemical concentration in food (in $\mu \mathrm{g} / \mathrm{kg}$ ), and $\sum k_{j, x, \text { out }}$ is the sum of the elimination rate constants (per day), pertaining to water (including urine), feces, growth dilution, and biotransformation. Concentration estimates in the model were based on wet weights and were transformed into lipid weight-based estimates using reported data on the whole-body lipid content. As the Arctic is a highly dynamic system, with algae blooms in spring and changes in the lipid content of zooplankton and species at higher trophic levels throughout the year, the assumption of a steady-state concentration may not be justified in a highly dynamic system such as the Arctic, especially for lower trophic levels. ${ }^{25}$ Furthermore, the OMEGA model only includes the main aquatic exposure routes and does not take into account any possible exposure of POPs through air (Text S1 in the Supporting Information (SI)).

Including Variability in Trophic Levels in OMEGA. The trophic level concept is predominantly used to evaluate food webs and food chains since these levels are relatively easy to define and allow for estimation of energy and contaminant flow through ecosystems. ${ }^{32}$ However, the use of discrete trophic levels fails to acknowledge complex interactions between organisms within a food web. In contrast, stable isotopic techniques provide a continuous measure of the trophic position, integrating contaminant flows from all different trophic pathways, leading to the species of interest. ${ }^{32}$ The use of relative trophic levels based on stable nitrogen isotopes $\left(\delta^{15} \mathrm{~N}\right)$ allows for the ecosystem and species-specific discrimination by means of unique nitrogen enrichment factors, and baseline correction. ${ }^{17}$ The isotopic signature of an organism alone does not provide sufficient information on absolute trophic position when comparing among multiple systems, as both the isotopic signature of baseline species and the nitrogen enrichment factors are location and food web specific. ${ }^{30}$ Therefore, we calculated the trophic position of target species based on the nitrogen enrichment factors and isotopic signatures of baseline species as reported in the literature, ${ }^{33}$ according to the following general model ${ }^{32,34}$

$$
\mathrm{TL}_{\text {consumer }}=\mathrm{TL}_{\text {baseline }}+\frac{\delta^{15} \mathrm{~N}_{\text {consumer }}-\delta^{15} \mathrm{~N}_{\text {baseline }}}{\Delta^{15} \mathrm{~N}}
$$

where $\mathrm{TL}_{\text {consumer }}$ represents the tropic level of the consumer, $\delta^{15} \mathrm{~N}_{\text {consumer }}$ represents its corresponding stable nitrogen isotope, $\delta^{15} \mathrm{~N}_{\text {baseline }}$ represents the measured stable nitrogen isotope of a species set at a baseline trophic level for a particular region and study (equal to $\mathrm{TL}_{\text {baseline }}$ ), and $\Delta^{15} \mathrm{~N}$ represents the enrichment factor of $\delta^{15} \mathrm{~N}$ across the food chain. As the variance in trophic levels induced by variation in $\delta^{15} \mathrm{~N}_{\text {consumer }}$ and $\Delta^{15} \mathrm{~N}$ between regions is higher than the variance between individuals, samples, and studies within one Arctic region, the present study only focused on bioaccumulation of POPs in the Svalbard Archipelago. ${ }^{33}$ Species from both pelagic and benthic food webs were considered since both food webs are important for top predators.

For each individual data record, the mean trophic level and its standard deviation were calculated based on eq 2 , including reported corresponding variation in $\delta^{15} \mathrm{~N}_{\text {consumer }}, \delta^{15} \mathrm{~N}_{\text {baseline, }}$ and $\Delta^{15} \mathrm{~N}$ by means of Monte Carlo simulation (1000 iterations). Trophic levels and standard deviations per data record were then used in constructing trophic level distributions per species by means of geometric averaging and taking the pooled standard deviation based on sample size (Table S5, Supporting Information). At each iteration, species were distributed over six discrete trophic level bins (ranging from 0 to 5), based on a trophic position randomly sampled from the species-specific probability distribution of the trophic level, which acted as direct input for 1000 biomagnification scenarios in OMEGA in a Monte Carlo simulation (see Text S2 in the Supporting Information). 


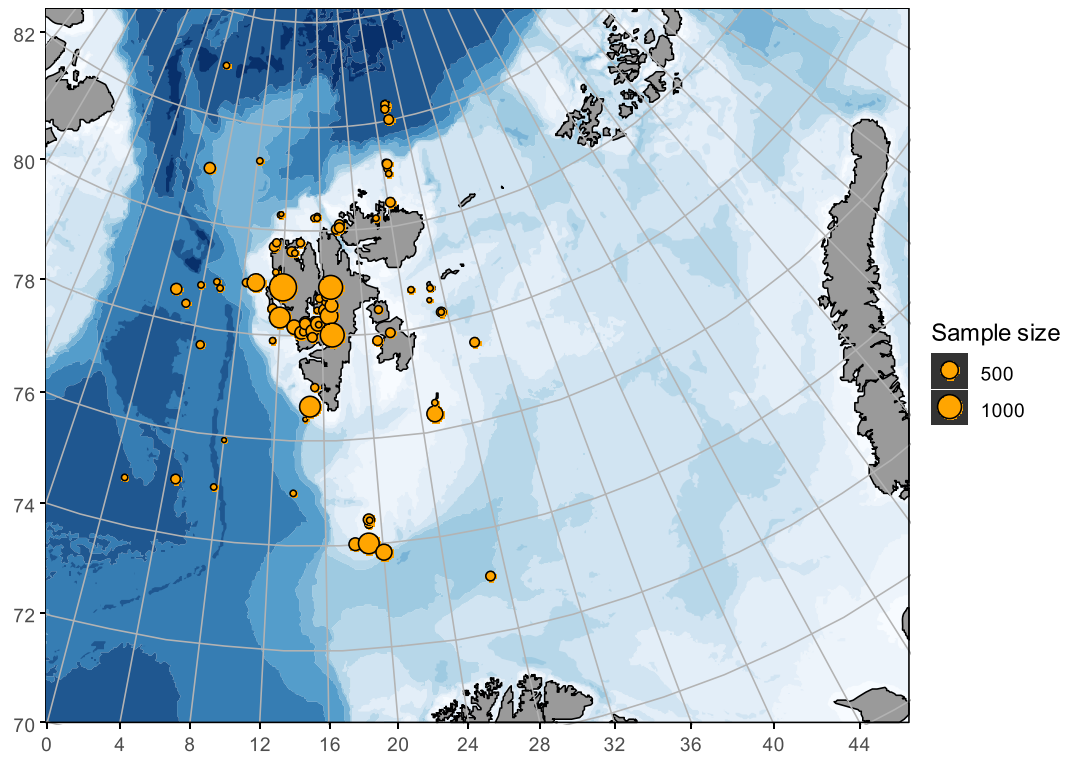

Figure 1. Locations of data records included in the Svalbard Archipelago, encompassing POP residue concentration data in Arctic biota, after truncation according to set criteria, obtained from a literature search. The size of the points indicates the sample size. ${ }^{39,40}$

Parametrization of the OMEGA Model. Equations pertaining to influxes and effluxes of the OMEGA model (eq 1) and corresponding parameter values, including the lipid content and the compound's octanol-water partition coefficient $\left(K_{\mathrm{ow}}\right)$, are provided in the Supporting Information (Text S1, Tables S1 and S2). Log-transformed $K_{\text {ow }}$ 's for the compounds were obtained using the experimental data from EPI-suite 4.1, disregarding any variation or uncertainty ${ }^{35}$ (see Supporting Information Table S2). Estimates for the bodyweight per trophic level was obtained through Hendriks et al. ${ }^{31}$ Whole-body lipid fractions were taken from the ICES database (http://ecosystemdata.ices.dk/). When no lipid percentage was reported, an average whole organism lipid fraction was taken based on the species group (see Table S3 in the Supporting Information). For mammals, an average wholebody lipid content of $30 \%$ was assumed. Compound-specific biotransformation rates for higher trophic levels ( $\mathrm{TL}>2)$ were based on median values reported by Arnot et al., ${ }^{36}$ which are standardized for a $10 \mathrm{~g}$ fish at a water temperature of $15{ }^{\circ} \mathrm{C}$ (see Table S4 for all biotransformation rates).

Since biotransformation rates tend to decrease with temperature, ${ }^{37,38}$ we accounted for their temperature dependence by assuming an Arrhenius-type of equation (eq S6 in the SI).

\section{EXPOSURE AND VALIDATION DATA}

Data Collection. Data on POP residues in marine biota around Svalbard $\left(72-85^{\circ} \mathrm{N}, 0-40^{\circ} \mathrm{E}\right)$ were compiled to calculate TMFs and to validate the OMEGA model. POP concentrations in both benthic and pelagic biota, transformed to $\mu \mathrm{g} / \mathrm{kg}$ lipid weight (l.w.), were downloaded from the database of the International Council for the Exploration of the Sea (ICES; http://ecosystemdata.ices.dk/) and complemented with the data from a literature search using the Web of Knowledge and Google Scholar. The search strings used in queries included names of the most recognized legacy POPs (including "p,p'-DDE”, "p,p'-DDT", "Hexachlorobenzene", "Dieldrin", or "PCB-153") or general terms and compound groups ("Persistent organic pollutants/compounds", "POPs",
"PCBs”, “DDTs”, “HCHs”, “PAHs”, “organochlorines”, "PFASs", or "PBDEs"). These were combined with general terms related to Arctic food webs ("Svalbard food web", "Svalbard", "Arctic", "Arctic food web", "Arctic ecosystem", "Arctic pelagic food web", or "Arctic benthic food web"), names of well-known Arctic pelagic and benthic species (both scientific (e.g., "Ursus maritimus", "Phoca hispida", or "Calanus hyperboreus") and their common names (e.g., "polar bear", "ringed seal", or "copepod")).

Data Treatment. Residue concentrations of POPs in biota were transformed to $\mu \mathrm{g} / \mathrm{kg}$ lipid weight (l.w.) using the reported whole-body lipid content (Table S3 in the Supporting Information). Duplicate values were removed using the Duplicate function in $\mathrm{R}$ statistics 3.4.1, based on the date of sampling, species, sex, location, sampling tissue, compound, and value. Although the obtained data were sampled throughout the year, due to the lack of data sampled in winter, only samples obtained for the months April until October and after the year 2000 were considered in further analysis. Three inclusion criteria were applied to the dataset to select compounds to be included in the dataset. As the OMEGA model is largely dependent on water concentrations, including a sufficient amount of water data $(n \geq 5)$, it is crucial for the model to reflect a natural system. However, data on POP concentrations in Arctic coastal and marine waters is grossly lacking in the literature. Therefore, as a first criterion (\#1), when no sufficient water concentration data were available $(n<5)$, water concentrations were estimated based on POP concentrations in zooplankton $(n \geq 5)$, reflecting the second trophic level of the Arctic food chain. These estimates were based on monitoring the data of POP residues in biota residing at the second trophic level and corresponding speciesspecific parameters. Given that, in some cases, the residue data were below the detection limit, a second criterion (\#2) was included, relating to the fraction censored data. Chemicals for which over $40 \%$ of the water data records fell below the detection limit were discarded. As a third criterion (\#3), we required that at least five species were monitored per compound to ensure that multiple species and trophic levels were represented in the model. As a fourth and final criterion 
(\#4), we required the remaining chemicals to cover at least four trophic levels. Reported POP concentrations in biota were geometrically averaged per species and location, and weighted according to the reported sample size (based on the amount of measurements) per data record (Figure 1).

Trophic Magnification Factor. The trophic magnification factor (TMF) is a typically used metric to assess the accumulation of contaminants in a food chain. Parallel to modeling biomagnification of POPs using the OMEGA model, TMFs were simulated (1000 iterations) based on the monitored average POP residue data per species and corresponding randomly sampled trophic levels per species taken from the constructed species-specific trophic level distributions, as described earlier. Unlike in the OMEGA model, TMFs were only calculated for ectothermic biota, as ectothermic animals are more likely to biomagnify chemicals than endothermic species. ${ }^{41}$ Concentrations of POPs can generally be described by a linear relationship ${ }^{15,17,41,42}$

$$
\log [C]=a+b \cdot \mathrm{TL}
$$

where $\log (C)$ is the $\log _{10}$-transformed lipid-normalized chemical concentration in ectothermic biota (phyto- and zooplankton, bivalves, and fish), aggregated per trophic level bin, $a$ reflects the intercept of the regression line and accounts for input of contaminants at the base of the food web, ${ }^{17}$ and $b$ is the regression slope coefficient. The TMF is then calculated from the regression slope $b$

$$
\mathrm{TMF}=10^{b}
$$

Model Validation and Performance. To asses model performance, the coefficient of efficiency ( $E$, dimensionless) was calculated for each persistent organic compound, through $^{43}$

$$
E=1-\frac{\sum_{i=1}^{n}\left(O_{i}-P_{i}\right)^{2}}{\sum_{i=1}^{n}\left(O_{i}-\bar{O}\right)^{2}}
$$

where $P_{i}$ reflects the log-transformed mean residue concentration per trophic level bin as predicted by the OMEGA model for simulation $i, O_{i}$ represents each corresponding logtransformed observed residue concentration, and $\bar{O}$ represents the log-transformed mean of all observed values within each iteration. The efficiency coefficient $E$ ranges from minus infinity to 1 , with a value of 1 indicating a perfect model estimation. A positive $E$ indicates that the model estimates are more accurate than the mean of the observed values, indicating a good fit. ${ }^{23,43}$ To summarize both random error and systematic bias, the root-mean-square-error for each model iteration was computed by geometrically averaging the squared differences between log-transformed observed and predicted values

$$
\mathrm{RMSE}=\sqrt{\frac{1}{n} \cdot \sum_{i=1}^{n}\left(O_{i}-P_{i}\right)^{2}}
$$

To summarize the relative error of the model, we computed the median symmetric accuracy $(\xi)$ per compound based on results from each iteration and the trophic level (eq 7), reflecting the typical percentage error of the predicted POP concentrations compared to the measured concentrations, without penalizing over- and underestimation differently, ${ }^{44,45}$ according to

$$
\xi=100 \cdot\left(e^{M(|\ln (\hat{y} / y)|)}-1\right)
$$

in which $\xi$ is based on the exponentiated median of the logtransformed predicted concentrations in biota $(\hat{y}, \mu \mathrm{g} / \mathrm{kg})$ and the log-transformed measured concentrations in biota $(y, \mu \mathrm{g} /$ $\mathrm{kg}) . \xi$ can be interpreted as a typical percentage error: a $\xi$ of $200 \%$, for example, indicates that predicted concentrations from OMEGA will typically be within a factor of 3 of the measured concentrations in Arctic biota. ${ }^{46}$ Finally, to assess the prediction bias of OMEGA, accounting for likely asymmetry in the prediction errors, we computed the symmetric signed percentage bias $(\mathrm{SSPB})^{45}$

$$
\operatorname{SSPB}=100 \cdot \operatorname{sgn}\left(M\left(\ln \left(\frac{\hat{y}}{y}\right)\right)\right) \cdot\left(e^{M(|\ln (\hat{y} / y)|)}-1\right)
$$

The SSPB may be interpreted similarly as the mean percentage error, with values below 0 indicating a systematic underprediction. Model performance metrics, as previously described, were compared among compound groups by performing a one-way analysis of variance (ANOVA). Compound groups were compared individually by performing a Fisher's least significant difference test. All work pertaining to the biomagnification modeling and model validation was performed in R statistics 3.4 .1 . $^{4}$

\section{RESULTS}

Exposure and Validation Data. The initial literature search on biota residue data resulted in 50 articles/reports, covering over 170 individual compounds from 9 chemical classes, encompassing 18000 data records (Table 1).

Table 1. Number of Data Records before and after

\begin{tabular}{|c|c|c|c|c|c|}
\hline & $\begin{array}{l}\text { initial } \\
\text { dataset }\end{array}$ & $\begin{array}{c}\text { \#1 } \\
\text { water } \\
\text { criterion }\end{array}$ & $\begin{array}{c}+\# 2 \\
\text { detection } \\
\text { limit } \\
\text { criterion }\end{array}$ & $\begin{array}{l}+\# 3 \text { species } \\
\text { concentration } \\
\text { data criterion }\end{array}$ & $\begin{array}{c}+\# 4 \\
\text { species } \\
\text { TL data } \\
\text { criterion }\end{array}$ \\
\hline $\begin{array}{l}\text { number of } \\
\text { data } \\
\text { records }\end{array}$ & 18318 & 16548 & 16548 & 16531 & 10044 \\
\hline $\begin{array}{l}\text { number of } \\
\text { compounds }\end{array}$ & 173 & 91 & 91 & 90 & 22 \\
\hline $\begin{array}{l}\text { number of } \\
\text { compound } \\
\text { groups }\end{array}$ & 9 & 8 & 8 & 8 & 6 \\
\hline $\begin{array}{l}\text { number of } \\
\text { species }\end{array}$ & 67 & 66 & 66 & 66 & 63 \\
\hline $\begin{array}{l}\text { number of } \\
\text { articles }\end{array}$ & 50 & 49 & 49 & 49 & 44 \\
\hline
\end{tabular}
Truncation of the Collected Data, According to the Four Criteria as Described in the Text (Relating to the Number of Species and TLs, the Number of Water/Zooplankton Data and the Amount of Censored Data) and the Presence of Sufficient Trophic Position Data

Application of the first three inclusion criteria, related to the number of concentration data, resulted in a secondary dataset of approximately 16500 data records (49 articles, encompassing 90 compounds for Svalbard (Table 1)). By including data on the trophic position, biomagnification could be modeled for a total of 22 compounds in Svalbard, based on 44 articles and 10000 data records (see the Supporting Information for the full reference list).

OMEGA Model Performance. Biomagnification could be modeled for a total of 22 compounds in the Svalbard 
Archipelago (Table S6 in the Supporting Information (SI)). Model results for each substance are shown in Figure S1 in the SI. In total, $60.8 \%$ of all predictions fell within a factor 5 of the observed values, with concentrations in biota being equally underestimated (in $18.8 \%$ of the cases) as well as overestimated (19.9\%) (Figure 2). As expected, a substantial

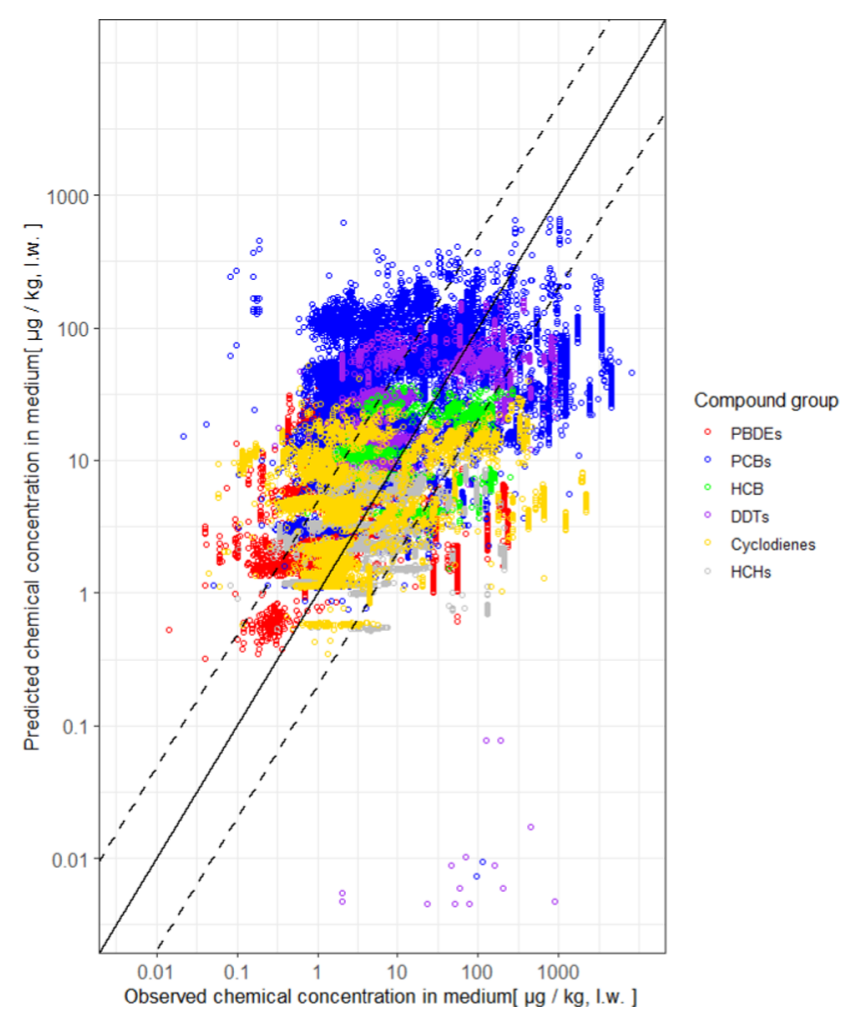

Figure 2. Observed POP concentrations in Svalbard biota versus predicted model estimates (based on 1000 Monte Carlo iterations per compound and five trophic bins per iteration). The dashed lines represent a factor of 5 under- or overestimation by the OMEGA model. The colors correspond to the compound groups.

concentration step between the water phase $(\mathrm{TL}=0)$ and phyto- and zooplankton ( $\mathrm{TL}=1$ ) was observed for almost all individual compounds (Figure S1, SI). Mean efficiencies (see eq 5) calculated for the OMEGA model, accounting for variation in the trophic position of Arctic species, ranged from -0.83 (CB-101) to 0.66 (CB-99) (Figure 3 left graph and Table S6). The majority of the studied compounds (18/22) had a positive mean efficiency value, implying that the model predictions were more accurate than the average of the observed concentrations. Overall, model runs for cyclodienes had the highest calculated averaged efficiencies $(0.38<E<$ $0.64)$, followed by runs for DDTs $(0.42<E<0.51)$ and PBDEs $(0.23>E<0.57)$. Lowest mean efficiencies were calculated for HCHs $(-0.38<E<0.57)$. No significant differences in model performance were observed between compound groups $(p=0.666$, one-way ANOVA). Calculated RMSEs were highest for CB-180 (2.72, Table S6) and lowest for CB-28 (0.86). The highest absolute RMSEs were found for cyclodienes $(1.82 \pm 0.64)$, followed by PBDEs $(1.74 \pm 0.02)$. However, again, no significant differences in RMSEs were observed among compound groups $(p=0.962$, one-way ANOVA). Median symmetric accuracies were calculated for all individual compounds, compound groups, and trophic level bins, reflecting the typical percentage error compared to the measured data. ${ }^{46}$ Overall, the typical prediction error of all model iterations was $288.49 \%$, implying that typically predictions were within a factor 3.9 from the observed concentrations. The lowest typical percentage error, and thus highest predictive power, was calculated for oxychlordane $(68.5 \%)$, while the highest typical percentage error was calculated for CB-180 (1081\%, Table S6 in the SI). Average model accuracies were highest for PBDEs $(\xi=145.37 \%)$, followed by $\mathrm{HCHs}(168.8 \%)$, while the highest average percentage errors were computed for PCBs (398.84\%) (Table 2). No statistically significant differences were observed in prediction errors among the modeled compound groups ( $p$ $=0.378$, one-way ANOVA). Evaluating model performance per trophic level bin revealed that the typical percentage errors were lowest for the first four trophic level bins (ranging from 110 to $220 \%$ ), and highest for the fifth trophic level. Despite the high standard deviation corresponding to the high prediction error of the fifth bin, a statistically significant difference in model performance, based on median symmetric accuracies, was observed between the fifth trophic level and the other trophic level bins ( $p=0.001$, one-way ANOVA with least significant difference). The average SSPB value across all simulations was 124.4, indicating an overestimation of the predictions relative to the monitored concentrations. The highest SSPB value, indicating the highest overestimation bias, was computed for CB-180 (888.15\%), while the lowest SSPB was found for $\mathrm{HCB}(-93.6 \%$, indicating an underestimation bias of a factor of almost 2). The SSPB closest to 0 , indicating best model performance, was found for model results for BDE$47(-1.55 \%)$ and CB-28 (12\%). PCBs (252.24\%) showed to have the highest SSPBs, while SSPBs closest to 0 were found for cyclodienes $(36.26 \%)$.

Including Trophic Variability. Variation in estimated steady-state concentrations in biota was assessed by calculating coefficients of variation (CVs) for efficiencies, RMSEs and TMFs (Tables 1 and S6 in the SI). The highest variability in efficiency induced by variability in trophic positions of species was observed for $\gamma-\mathrm{HCH}(138 \%)$, followed by CB-194 (134\%). The significantly highest CV was calculated for HCB (130\%), followed by HCHs (57.9\%), while the lowest CVs were calculated for cyclodienes (7.9\%) and DDTs (12.9\%). However, no significant differences were observed among the compound groups ( $p=0.221$, one-way ANOVA). Variation in RMSEs induced by variability in the trophic position of the included species showed to be highest for oxychlordane $(41.91 \%)$, and the lowest $\mathrm{CV}_{\mathrm{RMSE}}$ was calculated for CB-105 (4.7\%). Variability in measured POP concentrations (TMFs) was relatively high $(14.02 \pm 5.2 \%$, Table 1$)$. Both the variability in efficiencies and the variability in TMFs showed not to be correlated to the number of species included in analysis ( $p=0.47$ and 0.194 , respectively, linear regression model).

Trophic Magnification Factor. Overall, average TMFs calculated in the present study ranged from 1.5 (CB-99) to 6.84 (Oxychlordane). Cyclodienes had, on average, the highest magnification potential, followed by DDTs and HCBs, while lowest TMFs were found for HCHs (Table 2). TMFs did not differ significantly across compound groups $(p=0.588$, oneway ANOVA, Table 2). All assessed compounds in the present study are highly bioaccumulative (TMFs $>1, \log _{10}$ TMF $>$ $0^{48}$ ) (Figure $\mathrm{S} 2$ in the Supporting Information). 

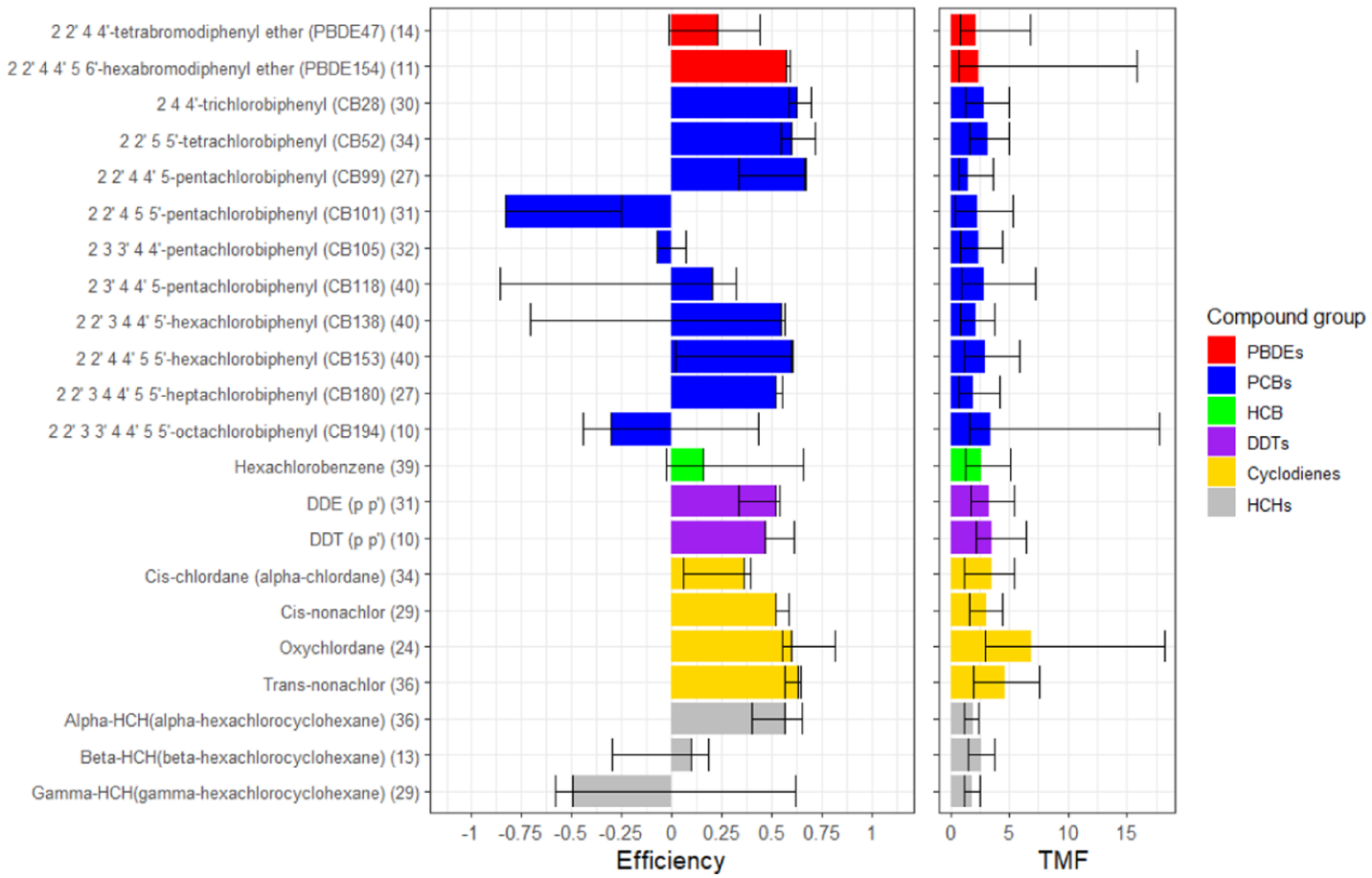

Figure 3. Model efficiencies including all species (left graph), empirical TMFs, including heterothermic species (right graph), and corresponding $95 \%$ confidence intervals due to variability in the trophic position of species, calculated for multiple compounds in Svalbard. The colors correspond to the compound groups. Additionally, the number of species included in the modeling practices per chemical is indicated for each substance between parentheses.

Table 2. Average Efficiencies, TMFs, Root-Mean-Squared-Errors (RMSEs), Median Symmetric Accuracies ( $\xi$ ), and Coefficients of Variation for Efficiencies and TMFs per Compound Group in the Svalbard Archipelago. Different Letters Indicate Significant Differences Between Groups ( $p<0.05$, ANOVA)

\begin{tabular}{|c|c|c|c|c|c|c|c|c|}
\hline & \multirow{2}{*}{$\begin{array}{l}\text { efficiency } \\
( \pm \text { S.E. })\end{array}$} & \multicolumn{7}{|l|}{$\log _{10}$ TMF } \\
\hline & & $( \pm$ S.E. $)$ & $\begin{array}{l}\text { RMSE of } \\
\text { OMEGA fit }\end{array}$ & $\xi$ & SSPB & $\mathrm{CV}_{\text {efficiency }}$ & $\mathrm{CV}_{\mathrm{RMSE}}$ & $\mathrm{CV}_{\mathrm{TMF}}$ \\
\hline PBDEs $(N=2)$ & $\begin{array}{l}0.399 \\
( \pm 0.243)^{\mathrm{A}}\end{array}$ & $\begin{array}{l}0.36 \\
( \pm 0.03)^{\mathrm{A}}\end{array}$ & $1.75\left( \pm 0.02^{\mathrm{A}}\right.$ & $\begin{array}{l}145.37 \\
\quad( \pm 69.19)^{\mathrm{A}}\end{array}$ & $\begin{array}{l}60.65 \% \\
( \pm 87.97)^{\mathrm{AB}}\end{array}$ & $\begin{array}{l}25.7 \% \\
\quad( \pm 33.3)^{\mathrm{B}}\end{array}$ & $\begin{array}{l}24.4 \% \\
\quad( \pm 0.8)^{\mathrm{A}}\end{array}$ & $\begin{array}{l}16.02 \% \\
( \pm 4.7)^{\mathrm{A}}\end{array}$ \\
\hline PCBs $(N=10)$ & $\begin{array}{l}0.301 \\
( \pm 0.405)^{\mathrm{A}}\end{array}$ & $\begin{array}{l}0.41 \\
\quad( \pm 0.11)^{\mathrm{A}}\end{array}$ & $1.72( \pm 0.54)^{\mathrm{A}}$ & $\begin{array}{l}398.84 \\
\quad( \pm 271.14)^{\mathrm{A}}\end{array}$ & $\begin{array}{l}252.84 \% \\
( \pm 256.71)^{\mathrm{A}}\end{array}$ & $\begin{array}{l}30.3 \% \\
\quad( \pm 45.2)^{\mathrm{B}}\end{array}$ & $\begin{array}{l}14.1 \% \\
\quad( \pm 8.3)^{\mathrm{A}}\end{array}$ & $15.5 \%( \pm 5.6)^{\mathrm{A}}$ \\
\hline $\mathrm{HCB}(N=1)$ & $0.183^{\mathrm{A}}$ & $0.41^{\mathrm{A}}$ & $1.55^{\mathrm{A}}$ & $251.23^{\mathrm{A}}$ & $-93.64 \%^{\mathrm{B}}$ & $130 \%^{\mathrm{A}}$ & $18.5 \%^{\mathrm{A}}$ & $9.3 \%{ }^{\mathrm{AB}}$ \\
\hline $\operatorname{DDTs}(N=2)$ & $\begin{array}{l}0.469 \\
\quad( \pm 0.065)^{\mathrm{A}}\end{array}$ & $\begin{array}{l}0.53 \\
\quad( \pm 0.02)^{\mathrm{A}}\end{array}$ & $1.45( \pm 0.37)^{\mathrm{A}}$ & $\begin{array}{l}228.34 \\
( \pm 64.01)^{\mathrm{A}}\end{array}$ & $68.3 \%( \pm 45.34)^{\mathrm{AB}}$ & $\begin{array}{l}12.9 \% \\
\quad( \pm 15.6)^{\mathrm{B}}\end{array}$ & $\begin{array}{l}16.7 \% \\
( \pm 5.6)^{\mathrm{A}}\end{array}$ & $\begin{array}{l}10.9 \% \\
\quad( \pm 0.38)^{\mathrm{AB}}\end{array}$ \\
\hline $\begin{array}{l}\text { cyclodienes } \\
(N=4)\end{array}$ & $\begin{array}{l}0.535 \\
\quad( \pm 0.12)^{\mathrm{A}}\end{array}$ & $\begin{array}{l}0.65 \\
\quad( \pm 0.15)^{A}\end{array}$ & $1.83( \pm 0.65)^{\mathrm{A}}$ & $\begin{array}{l}190.55 \\
( \pm 110.07)^{\mathrm{A}}\end{array}$ & $\begin{array}{l}36.26 \% \\
\quad( \pm 54.59)^{\mathrm{AB}}\end{array}$ & $7.9 \%( \pm 7.7)^{\mathrm{B}}$ & $\begin{array}{l}25.9 \% \\
\quad( \pm 12.1)^{\mathrm{A}}\end{array}$ & $15.9 \%( \pm 4.1)^{\mathrm{A}}$ \\
\hline $\mathrm{HCHs}(N=3)$ & $\begin{array}{l}0.092 \\
\quad( \pm 0.47)^{\mathrm{A}}\end{array}$ & $\begin{array}{l}0.33 \\
\quad( \pm 0.08)^{\mathrm{A}}\end{array}$ & $1.57( \pm 0.40)^{\mathrm{A}}$ & $168.35( \pm 3.71)^{\mathrm{A}}$ & $\begin{array}{l}-33.57 \% \\
( \pm 53.95)^{\mathrm{B}}\end{array}$ & $\begin{array}{l}57.9 \% \\
\quad( \pm 70.1)^{\mathrm{AB}}\end{array}$ & $\begin{array}{l}13.2 \% \\
( \pm 18.6)^{\mathrm{A}}\end{array}$ & $8.6 \%( \pm 3.9)^{\mathrm{AB}}$ \\
\hline total & $0.342( \pm 0.33)$ & $\begin{array}{l}0.45 \\
\quad( \pm 0.12)\end{array}$ & $1.69( \pm 0.47)$ & $\begin{array}{l}284.29 \% \\
\quad( \pm 213.76)\end{array}$ & $124.41( \pm 212.75)$ & $32.5 \%( \pm 46)$ & $18.3 \%( \pm 9.6)$ & $14.02 \%( \pm 5.2)$ \\
\hline
\end{tabular}

\section{DISCUSSION}

Our study shows how variation in the trophic position of species influences modeling performance of a biomagnification model when applied to modeling POPs in Arctic ecosystems. Considerable variation in trophic position was observed for the species included in the present study, resulting in varying model performance across compound groups (given the large differences in $\mathrm{CV}_{\text {efficiency }}($ Table 2)). However, this trophic variation did not have major implications for bioaccumulation, given the relatively low CVs found for TMF. Although biomagnification in Arctic marine food webs has been thoroughly examined on a relatively small temporary and spatial scale in separate case studies, implications of intraspecific variation in trophic levels on biomagnification on larger scales are often disregarded. ${ }^{49}$ As in the present study, species were binned according to their trophic level, presumably feeding upon the previous bin, we stress that the food webs used in the present study do not necessarily reflect natural Arctic food webs. However, nitrogen stable isotopes of species on the basis of the trophic level estimation were compared to baseline species in the same system, thus representing a representative trophic level. Furthermore, stable nitrogen isotopic signatures of primary producers at the base of the food web are considered to be relatively spatially and temporally similar, hence the use of a fixed baseline trophic position (2). ${ }^{50}$

OMEGA Model Performance. For the majority of modeled compounds (18/22), efficiencies pertaining to modeling biomagnification along Arctic marine food chains 
were positive, indicating that the mechanistic OMEGA model fits the monitoring data more accurately than taking the average of the observed concentrations. However, as with the $R^{2}$, the coefficient of variation $E$ is highly sensitive to outliers. ${ }^{43}$ Concentration steps observed in the present study have been reported in data of several previous studies focusing on both Arctic and temperate food webs, ${ }^{51-53}$ and may be explained by POP concentrations in biota at the base of the food web being in (near-)equilibrium with dissolved water concentrations. ${ }^{51}$ In the present study, no major fluctuations in modeled concentrations at the base of the food web occurred, except for compounds lacking sufficient concentration data on species residing at $\mathrm{TL}=1$ (e.g., certain PBDEs, Figure $\mathrm{S} 1$ in the SI). The OMEGA model predicted less well for species residing at higher trophic positions (including fish and marine mammals) ( TL $=4$ and 5, Table S7 in SI). In the present study, we included biotransformation rates, based on values normalized for $10 \mathrm{~g}$ fish and a water temperature of $15^{\circ} \mathrm{C}^{36}$ As biotransformation increases with increasing temperatures, ${ }^{23,54}$ biotransformation may be lower in the Arctic. To account for changes in biotransformation associated with lower atmospheric temperatures, we transformed our biotransformation rates using an Arrhenius function. ${ }^{13,55}$ However, biotransformation rates in all species were based on those for fish, so we did not take into account differences in species thermal groups. Although temperature especially affects the biotransformation rate of poikilotherms (in this case, fish), it also has some influence on the metabolic rate in homeotherms (mammals). ${ }^{56}$ In the present study, biotransformation rates may be different for marine mammals residing at the higher trophic positions in the food chain.

Overall, median prediction errors for all compounds by OMEGA were within a factor of 6 from the observed concentrations $(\xi<500 \%)$. An average SSPB of $124 \%$ was observed, indicating an overestimation when concerning all model predictions. Large standard deviations in $\xi_{\mathrm{s}}$ and SSPBs were observed within all model predictions, as well as within compound groups, and no statistically significant differences were observed in $\xi$ s and SSPBs among the compound groups. Overall, HCHs showed to have the lowest efficiencies, indicating a poor fit. However, this may likely be due to the low calculated efficiency for $\mathrm{HCH}-\gamma$ as average RMSEs, $\xi$ s and SSPBs showed to be relatively low for these compounds. All $\mathrm{HCH}$ included in the present study had relatively low octanol-water partition coefficients $\left(\log K_{\mathrm{ow}}=4.14\right.$, compared to $K_{\mathrm{ow}}$ ranging from 5.48 to 8.68 for other compounds), limiting partitioning of a chemical from water into lipids, and thus bioaccumulation potential. ${ }^{57}$ Although $\mathrm{HCHs}$ are efficiently metabolized in vertebrates at higher trophic levels, i.e., fish and marine mammals, gut microbial degradation may also play a role in bioaccumulation of $\mathrm{HCHs}$ in the Arctic food chain. $^{58}$

Trophic Magnification Factor. Interpretation of field data may be sensitive to bias induced by uncertainty in trophic interactions, limited statistical power, and ecosystem-specific factors, such as water salinity and temperature, affecting the water solubility and organic matter partitioning of POPs. ${ }^{17,19,59-61}$ In the present study, TMF values computed for individual POPs had an average CV of $14.01 \%$. These TMFs take into account the observed variation in stable nitrogen isotopes as well as in the nitrogen fractionation factors used and the choice of baseline species. ${ }^{33}$ Instead of taking a TMF based on a single food web, variability in TMFs can be quantified by computing distributions based on TMF simulations. ${ }^{15}$ Rather than applying numeric pass/fail criteria to single field-TMFs, it is then possible to quantify the risk of certain chemicals exceeding these criteria based on a more wider background. ${ }^{48}$ However, this may not yet be applicable in a regulatory context as knowledge is currently lacking on whether the variability in simulated TMFs is the result of natural variation in relevant processes or measurement errors, poorly defined concepts, and statistical analyses. ${ }^{15}$ Given the rule of the thumb that TMFs $<1$ indicate poorly bioaccumulative substances, ${ }^{48}$ an inadequate choice of species in biomagnification modeling and incorrect use of trophic levels can result in chemicals being characterized as poorly bioaccumulative. Examples in the present study are BDE-154 and CB-99, for which 22.4 and $17.0 \%$ of all simulated TMFs fall below 1, respectively (Table S6, SI). Problems may arise in calculating TMFs when food webs include both poikilotherms and homeotherms, which is often the case with the Arctic pelagic food webs. ${ }^{60}$ This problem was avoided by including only the first three trophic levels in the TMF calculations, excluding birds and mammals. Variation in biomagnification may be induced by different individual-specific covariates, such as length or lipid content, or methodological differences pertaining to the sampling protocol (i.e., sampling tissue). ${ }^{25,62,63}$ Computed median TMFs in this study were slightly lower than-but within a factor of 2 of-the corresponding obtained TMFs gathered by Walters et al. ${ }^{41}$ (see Table S8 in the Supporting Information). While standard errors for TMFs in the study by Walters et al. were relatively high, our computed TMFs were not significantly different from these measured TMFs. The analysis in the present study, as well as the study done by Walters et al. reveals PCBs as the compound group with the highest bioaccumulative potential. In contrast to the present study, the study by Walters et al. focused on TMFs measured in temperate zones. As mentioned previously, biomagnification of nonmetabolizable POPs is thought to be an exothermic process, implying that biomagnification decreases with increasing temperature. ${ }^{64}$ Temperature may not only influence POP concentrations in biota because of its influence on metabolic (biotransformation) rate but may also affect the excretion rate by modifying the lipid content of the animal, especially in poikilothermic animals. ${ }^{56}$ If this is the case, measured POPs are expected to be higher in Arctic biota, compared to temperate zones. This was not the case in the present study, reporting lower TMFs based on monitoring data for the Arctic than TMFs reported in temperate zones (by Walters et al., 2016). However, next to the climatic zone, other environmental and methodological parameters may influence the calculation of $\mathrm{TMF}^{41}$ In the study by Walters et al. TMFs in the Arctic zones were based on both ectothermic and endothermic organisms, while in the present study, only ectothermic species were considered in the TMF calculation. The same study found that TMFs are lower in food webs containing only ectotherms (or when TMFs are based on only ectothermic species, as in the present study), independent of latitude. ${ }^{41}$ Furthermore, they found that TMFs were more variable in marine ecosystems compared to freshwater ecosystems.

Implications and Recommendations. Overall, OMEGA predicted reasonably well for the compounds included in the present study, with efficiencies for 18 out of 22 compounds being positive. Variation in the trophic position of species, due to both natural processes (seasonality) and methodological 
differences (choice of baseline species and nitrogen fractionation factor), accounted for up to a $25 \%$ variability in the model performance metrics. Considerable amounts of data were required, pertaining to both the studied chemicals (e.g., residues in biota and octanol-water partition coefficients) and the species (e.g., body mass and trophic position or stable nitrogen isotopic data) to realistically quantify the implications of intra- and inter-specific trophic variability on biomagnification of POPs in Arctic food webs. In particular, data on POP concentrations in zooplankton were relatively sparse, disallowing biomagnification modeling for many compounds. As several criteria were set to increase statistical robustness (representativeness) of the model, the demand for more data increased accordingly.

Application of toxicokinetic mass balance biomagnification models in Arctic ecosystems is rare, due to the variability of metabolic rates and rates of decay at lower temperatures and the confirmed high seasonal variability in the biological activity of Arctic organisms and, therefore, biomagnification. ${ }^{25,65}$ To our knowledge, we were the first to include trophic variability in predicting biomagnification of chemicals in Arctic ecosystems using a mechanistic biomagnification model, including temperature-dependent biotransformation rates. As variation in modeling performance results showed to be relatively low, we may conclude that the variation in the trophic position of Arctic species may not have a major influence on the degree of biomagnification of POPs, based on evaluation of the in silico biomagnification model, the OMEGA model.

\section{ASSOCIATED CONTENT}

\section{(s) Supporting Information}

The Supporting Information is available free of charge at https://pubs.acs.org/doi/10.1021/acs.est.9b06666.

Parametrization of the OMEGA bioaccumulation model (Text S1); including trophic variation in OMEGA modeling (Text S2); parameters and variables used in the present study in OMEGA bioaccumulation model for the estimation of influx and efflux rate constants (Table S1); Log $K_{\mathrm{ow}}$ values used per chemical (Table S2); average whole-body lipid percentage per species group (Table S3); biotransformation rates for POPs included in the present study (Table S4); mean and standard deviation of the distributions of trophic levels of species in Svalbard (Table S5); median trophic magnification factors (TMFs), computed efficiencies, RMSEs, including the $95 \%$ confidence intervals, median symmetric accuracies $(\xi)$, symmetric signed percentage bias (SSPB), percentage of TMFs below 1 (indicating poor bioaccumulation), and coefficients of variation (CVs) for the Svalbard Archipelago (Table S6); average median symmetric accuracies for the OMEGA model per compound group and trophic level bin in the Svalbard Archipelago (Table S7); TMFs computed in the present study versus the measured TMF averages reported by Walters et al. (2016) (Table S8); bioaccumulation of multiple POPs and PAHs in Svalbard as predicted by the OMEGA bioaccumulation model (Figure S1); trophic magnification factors (TMFs) and linear trends based on exothermic species only for the modeled compounds in the present study (Figure S2); efficiencies, TMFs, and median symmetric accuracies compared to the number of species included in the present study (Figure S3) (PDF)

Raw data sheets (XLSX)

$\mathrm{R}$ script related to modeling bioaccumulation of POPs (TXT)

\section{AUTHOR INFORMATION}

\section{Corresponding Author}

Renske P. J. Hoondert - Department of Environmental Science, Radboud University, 6525 AJ Nijmegen, The Netherlands; ○ orcid.org/0000-0001-6990-9851; Phone: +31-(0)24-365 23 93; Email: R.Hoondert@science.ru.nl

\section{Authors}

Nico W. van den Brink - Division of Toxicology, Wageningen University, 6700 EA Wageningen, The Netherlands

Martine J. van den Heuvel-Greve - Wageningen Marine Research, 4400 AB Yerseke, The Netherlands

AdM. J. Ragas - Department of Environmental Science, Radboud University, 6525 AJ Nijmegen, The Netherlands; Faculty of Management, Science and Technology, Open University, 6401 DL Heerlen, The Netherlands

A. Jan Hendriks - Department of Environmental Science, Radboud University, 6525 AJ Nijmegen, The Netherlands

Complete contact information is available at:

https://pubs.acs.org/10.1021/acs.est.9b06666

\section{Notes}

The authors declare no competing financial interest.

\section{ACKNOWLEDGMENTS}

This research project was funded by the Netherlands Organization for Scientific Research (NWO) under the Netherlands Polar Program (NPP), Project no.: 866.13.007.

\section{REFERENCES}

(1) Horri, K.; Alfonso, S.; Cousin, X.; Munschy, C.; Loizeau, V.; Aroua, S.; Bégout, M.-L.; Ernande, B. Fish life-history traits are affected after chronic dietary exposure to an environmentally realistic marine mixture of PCBs and PBDEs. Sci. Total Environ. 2018, 610$611,531-545$.

(2) Rattner, B. A. History of wildlife toxicology. Ecotoxicology 2009, $18,773-783$.

(3) Nuijten, R. J. M.; Hendriks, A. J.; Jenssen, B. M.; Schipper, A. M. Circumpolar contaminant concentrations in polar bears (Ursus maritimus) and potential population-level effects. Environ. Res. 2016, $151,50-57$.

(4) Lair, S.; Measures, L.; Martineau, D. Pathologic findings and trends in mortality in the beluga (Delphinapterus leucas) population of the St Lawrence Estuary, Quebec, Canada, from 1983 to 2012. Vet. Pathol. 2016, 53, 22-36.

(5) Wania, F. Assessing the potential of persistent organic chemicals for long-range transport and accumulation in polar regions. Environ. Sci. Technol. 2003, 37, 1344-1351.

(6) De Laender, F.; Hammer, J.; Hendriks, A. J.; Soetaert, K.; Janssen, C. Combining monitoring data and modeling identifies PAHs as emerging contaminants in the Arctic. Environ. Sci. Technol. 2011, 45, 9024-9029.

(7) US EPA. DDT: A Review of Scientific and Economic Aspects of the Decision to Ban Its Use as a Pesticide Prepared for the Committee on Appropriations of the US House of Representatives by the Environmental Protection Agency, 1975.

(8) Cabrerizo, A.; Muir, D. C. G.; De Silva, A. O.; Wang, X.; Lamoureux, S. F.; Lafrenière, M. J. Legacy and Emerging Persistent Organic Pollutants (POPs) in Terrestrial Compartments in the High 
Arctic: Sorption and Secondary Sources. Environ. Sci. Technol. 2018, 52, 14187-14197.

(9) AMAP. AMAP Assessment 2002: Persistent Organic Pollutants in the Arctic; Arctic Monitoring and Assessment Programme (AMAP): Oslo, Norway, 2004.

(10) Macdonald, R. W.; Harner, T.; Fyfe, J. Recent climate change in the Arctic and its impact on contaminant pathways and interpretation of temporal trend data. Sci. Total Environ. 2005, 342, 5-86.

(11) Loganathan, B. G.; Lam, P. K.-S. Global Contamination Trends of Persistent Organic Chemicals; CRC Press, 2011.

(12) Kelly, B. C.; Ikonomou, M. G.; Blair, J. D.; Gobas, F. A. Bioaccumulation behaviour of polybrominated diphenyl ethers (PBDEs) in a Canadian Arctic marine food web. Sci. Total Environ. 2008, 401, 60-72.

(13) Hop, H.; Borgå, K.; Gabrielsen, G. W.; Kleivane, L.; Skaare, J. $\mathrm{U}$. Food web magnification of persistent organic pollutants in poikilotherms and homeotherms from the Barents Sea. Environ. Sci. Technol. 2002, 36, 2589-2597.

(14) Borgå, K.; Fisk, A. T.; Hoekstra, P. F.; Muir, D. C. Biological and chemical factors of importance in the bioaccumulation and trophic transfer of persistent organochlorine contaminants in arctic marine food webs. Environ. Toxicol. Chem. 2004, 23, 2367-2385.

(15) Starrfelt, J.; Borgå, K.; Ruus, A.; Fjeld, E. Estimating Trophic Levels and Trophic Magnification Factors Using Bayesian Inference. Environ. Sci. Technol. 2013, 47, 11599-11606.

(16) Ehrlich, G.; Jöhncke, U.; Drost, W.; Schulte, C. Problems faced when evaluating the bioaccumulation potential of substances under REACH. Integr. Environ. Assess. Manage. 2011, 7, 550-558.

(17) Borgå, K.; Kidd, K. A.; Muir, D. C.; Berglund, O.; Conder, J. M.; Gobas, F. A.; Kucklick, J.; Malm, O.; Powell, D. E. Trophic magnification factors: Considerations of ecology, ecosystems, and study design. Integr. Environ. Assess. Manage. 2012, 8, 64-84.

(18) Hendriks, A. J.; Heikens, A. The power of size. 2. Rate constants and equilibrium ratios for accumulation of inorganic substances related to species weight. Environ. Toxicol. Chem. 2001, 20, 1421-1437.

(19) Kim, J.; Gobas, F. A. P. C.; Arnot, J. A.; Powell, D. E.; Seston, R. M.; Woodburn, K. B. Evaluating the roles of biotransformation, spatial concentration differences, organism home range, and field sampling design on trophic magnification factors. Sci. Total Environ. 2016, 551-552, 438-451.

(20) Opperhuizen, A. Bioaccumulation Kinetics: Experimental Data and Modelling. Organic Micropollutants in the Aquatic Environment; Springer, 1991; pp 61-70.

(21) Gobas, F. A. A model for predicting the bioaccumulation of hydrophobic organic chemicals in aquatic food-webs: application to Lake Ontario. Ecol. Modell. 1993, 69, 1-17.

(22) Mackay, D.; Celsie, A. K. D.; Powell, D. E.; Parnis, J. M. Bioconcentration, bioaccumulation, biomagnification and trophic magnification: a modelling perspective. Environ. Sci.: Processes Impacts 2018, 20, 72-85.

(23) De Hoop, L.; Huijbregts, M. A.; Schipper, A. M.; Veltman, K.; De Laender, F.; Viaene, K. P.; Klok, C.; Hendriks, A. J. Modelling bioaccumulation of oil constituents in aquatic species. Mar. Pollut. Bull. 2013, 76, 178-186.

(24) Korsman, J. C.; Schipper, A. M.; de Vos, M. G.; van den Heuvel-Greve, M. J.; Vethaak, A. D.; de Voogt, P.; Hendriks, A. J. Modeling bioaccumulation and biomagnification of nonylphenol and its ethoxylates in estuarine-marine food chains. Chemosphere 2015, 138, 33-39.

(25) De Laender, F.; van Oevelen, D.; Frantzen, S.; Middelburg, J. J.; Soetaert, K. Seasonal PCB bioaccumulation in an Arctic marine ecosystem: a model analysis incorporating lipid dynamics, food-web productivity and migration. Environ. Sci. Technol. 2010, 44, 356-361.

(26) Hargrave, B. T.; Phillips, G. A.; Vass, W. P.; Bruecker, P.; Welch, H. E.; Siferd, T. D. Seasonality in Bioaccumulation of Organochlorines in Lower Trophic Level Arctic Marine Biota. Environ. Sci. Technol. 2000, 34, 980-987.
(27) Carmack, E.; Wassmann, P. Food webs and physical-biological coupling on pan-Arctic shelves: unifying concepts and comprehensive perspectives. Prog. Oceanogr. 2006, 71, 446-477.

(28) Blanchard, A. L.; Day, R. H.; Gall, A. E.; Aerts, L. A.; Delarue, J.; Dobbins, E. L.; Hopcroft, R. R.; Questel, J. M.; Weingartner, T. J.; Wisdom, S. S. Ecosystem variability in the offshore northeastern Chukchi Sea. Prog. Oceanogr. 2017, 159, 130-153.

(29) Chen, C.; Kamman, N.; Williams, J.; Bugge, D.; Taylor, V.; Jackson, B.; Miller, E. Spatial and temporal variation in mercury bioaccumulation by zooplankton in Lake Champlain (North America). Environ. Pollut. 2012, 161, 343-349.

(30) Vander Zanden, M. J.; Shuter, B. J.; Lester, N.; Rasmussen, J. B. Patterns of food chain length in lakes: a stable isotope study. Am. Nat. 1999, 154, 406-416.

(31) Hendriks, A. J.; van der Linde, A.; Cornelissen, G.; Sijm, D. T. The power of size. 1. Rate constants and equilibrium ratios for accumulation of organic substances related to octanol-water partition ratio and species weight. Environ. Toxicol. Chem. 2001, 20, 13991420.

(32) Post, D. M. Using stable isotopes to estimate trophic position: models, methods, and assumptions. Ecology 2002, 83, 703-718.

(33) Hoondert, R. P. J.; van den Brink, N. W.; van den HeuvelGreve, M. J.; Ragas, A. M. J.; Hendriks, A. J. Variability in nitrogenderived trophic levels of Arctic marine biota, in preparation.

(34) Jardine, T. D.; Kidd, K. A.; Fisk, A. T. Applications, considerations, and sources of uncertainty when using stable isotope analysis in ecotoxicology. Environ. Sci. Technol. 2006, 40, 7501-7511.

(35) US EPA. Estimation Programs Interface Suite ${ }^{T M}$ for Microsoft Windows, 4.1. United States Environmental Protection Agency: Washington, DC, 2017.

(36) Arnot, J. A.; Mackay, D.; Parkerton, T. F.; Bonnell, M. A database of fish biotransformation rates for organic chemicals. Environ. Toxicol. Chem. 2008, 27, 2263-2270.

(37) Carrasco-Navarro, V.; Jæger, I.; Honkanen, J.; Kukkonen, J.; Carroll, J.; Camus, L. J. Bioconcentration, biotransformation and elimination of pyrene in the arctic crustacean Gammarus setosus (Amphipoda) at two temperatures. Mar. Environ. Res. 2015, 110, 101-109.

(38) Fahd, F.; Veitch, B.; Khan, F. Arctic marine fish 'biotransformation toxicity' model for ecological risk assessment. Mar. Pollut. Bull. 2019, 142, 408-418.

(39) Vihtakari, M. PlotSvalbard: PlotSvalbard-Plot Research Data from Svalbard on maps, 2019.

(40) Jakobsson, M.; Mayer, L.; Coakley, B.; Dowdeswell, J. A.; Forbes, S.; Fridman, B.; Hodnesdal, H.; Noormets, R.; Pedersen, R.; Rebesco, M. J. G. R. L. The international bathymetric chart of the Arctic Ocean 530(IBCAO) version 3.0, 2012, 39(12).

(41) Walters, D. M.; Jardine, T. D.; Cade, B. S.; Kidd, K. A.; Muir, D. C. G.; Leipzig-Scott, P. Trophic Magnification of Organic Chemicals: A Global Synthesis. Environ. Sci. Technol. 2016, 50, 4650-4658.

(42) Franklin, J. How reliable are field-derived biomagnification factors and trophic magnification factors as indicators of bioaccumulation potential? Conclusions from a case study on per-and polyfluoroalkyl substances. Integr. Environ. Assess. Manage. 2016, 12, $6-20$.

(43) Legates, D. R.; McCabe, G. J. Evaluating the use of "goodnessof-fit" measures in hydrologic and hydroclimatic model validation. Water Resour. Res. 1999, 35, 233-241.

(44) Morley, S. K. Alternatives to Accuracy and Bias Metrics Based on Percentage Errors for Radiation Belt Modeling Applications; Los Alamos National Lab (LANL): Los Alamos, NM, 2016.

(45) Morley, S. K.; Brito, T. V.; Welling, D. T. Measures of model performance based on the log accuracy ratio. Space Weather 2018, 16, $69-88$.

(46) Oldenkamp, R.; Hoeks, S.; Čengić, M.; Barbarossa, V.; Burns, E. E.; Boxall, A. B. A.; Ragas, A. M. J. A High-Resolution Spatial Model to Predict Exposure to Pharmaceuticals in European Surface Waters: ePiE. Environ. Sci. Technol. 2018, 52, 12494-12503. 
(47) R Core Team R: A Language and Environment for Statistical Computing, R Foundation for Statistical Computing: Vienna, 2017.

(48) Mackay, D.; Celsie, A. K. D.; Arnot, J. A.; Powell, D. E. Processes influencing chemical biomagnification and trophic magnification factors in aquatic ecosystems: Implications for chemical hazard and risk assessment. Chemosphere 2016, 154, 99-108.

(49) Powell, D. E.; Schøyen, M.; Øxnevad, S.; Gerhards, R.; Böhmer, T.; Koerner, M.; Durham, J.; Huff, D. W. Bioaccumulation and trophic transfer of cyclic volatile methylsiloxanes (cVMS) in the aquatic marine food webs of the Oslofjord, Norway. Sci. Total Environ. 2018, 622-623, 127-139.

(50) Carscallen, W. M. A.; Vandenberg, K.; Lawson, J. M.; Martinez, N. D.; Romanuk, T. N. Estimating trophic position in marine and estuarine food webs. Ecosphere 2012, 3, 1-20.

(51) Sobek, A.; McLachlan, M. S.; Borgå, K.; Asplund, L.; Lundstedt-Enkel, K.; Polder, A.; Gustafsson, Ö. A comparison of PCB bioaccumulation factors between an arctic and a temperate marine food web. Sci. Total Environ. 2010, 408, 2753-2760.

(52) Sobek, A.; Gustafsson, Ö. Latitudinal fractionation of polychlorinated biphenyls in surface seawater along a $62 \mathrm{~N}-89 \mathrm{~N}$ transect from the southern Norwegian Sea to the North Pole area. Environ. Sci. Technol. 2004, 38, 2746-2751.

(53) Sobek, A.; Reigstad, M.; Gustafsson, Ö. Partitioning of polychlorinated biphenyls between Arctic seawater and sizefractionated zooplankton. Environ. Toxicol. Chem. 2006, 25, 17201728.

(54) Buckman, A. H.; Brown, S. B.; Small, J.; Muir, D. C.; Parrott, J.; Solomon, K. R.; Fisk, A. T. Role of temperature and enzyme induction in the biotransformation of polychlorinated biphenyls and bioformation of hydroxylated polychlorinated biphenyls by rainbow trout (Oncorhynchus mykiss). Environ. Sci. Technol. 2007, 41, 38563863.

(55) Boon, J. P.; Eijgenraam, F.; Everaarts, J. M.; Duinker, J. C. A structure-activity relationship (SAR) approach towards metabolism of PCBs in marine animals from different trophic levels. Mar. Environ. Res. 1989, 27, 159-176.

(56) Norstrom, R. J.; Clark, T. P.; Enright, M.; Leung, B.; Drouillard, K. G.; Macdonald, C. R. ABAM, a Model for Bioaccumulation of POPs in Birds: Validation for Adult Herring Gulls and Their Eggs in Lake Ontario. Environ. Sci. Technol. 2007, 41, 4339-4347.

(57) Mackay, D.; Arnot, J. A.; Gobas, F. A.; Powell, D. E. Mathematical relationships between metrics of chemical bioaccumulation in fish. Environ. Toxicol. Chem. 2013, 32, 1459-1466.

(58) Falconer, R. L.; Bidleman, T. F.; Gregor, D. J. Air-water gas exchange and evidence for metabolism of hexachlorocyclohexanes in Resolute Bay, N.W.T. Sci. Total Environ. 1995, 160-161, 65-74.

(59) Schwarzenbach, R. P.; Gschwend, P. M. Environmental Organic Chemistry; John Wiley \& Sons, 2016.

(60) Burkhard, L. P.; Borgå, K.; Powell, D. E.; Leonards, P.; Muir, D. C. G.; Parkerton, T. F.; Woodburn, K. B. Improving the Quality and Scientific Understanding of Trophic Magnification Factors (TMFs). Environ. Sci. Technol. 2013, 47, 1186-1187.

(61) Conder, J. M.; Gobas, F. A.; Borgå, K.; Muir, D. C.; Powell, D. E. Use of trophic magnification factors and related measures to characterize bioaccumulation potential of chemicals. Integr. Environ. Assess. Manage. 2012, 8, 85-97.

(62) Visha, A.; Gandhi, N.; Bhavsar, S. P.; Arhonditsis, G. B.; Bayesian, A. assessment of the mercury and PCB temporal trends in lake trout (Salvelinus namaycush) and walleye (Sander vitreus) from lake Ontario, Ontario, Canada. Ecotoxicol. Environ. Saf. 2015, 117, 174-186.

(63) Curtis, A. N.; Bugge, D. M.; Buckman, K. L.; Feng, X.; Faiia, A.; Chen, C. Y. Influence of sample preparation on estuarine macrofauna stable isotope signatures in the context of contaminant bioaccumulation studies. J. Exp. Mar. Biol. Ecol. 2017, 493, 1-6.

(64) Muijs, B.; Jonker, M. T. Temperature-dependent bioaccumulation of polycyclic aromatic hydrocarbons. Environ. Sci. Technol. 2009, 43, 4517-4523.
(65) Ursin, E. The tropical, the temperate and the arctic seas as media for fish production. Dana 1984, 3, 43-60. 